ACCEPTED MANUSCRIPT

\title{
Osteogenic effects of simvastatin-loaded mesoporous titania thin films
}

To cite this article before publication: Miriam Lopez-Alvarez et al 2017 Biomed. Mater. in press https://doi.org/10.1088/1748-605X/aa95f1

\section{Manuscript version: Accepted Manuscript}

Accepted Manuscript is "the version of the article accepted for publication including all changes made as a result of the peer review process, and which may also include the addition to the article by IOP Publishing of a header, an article ID, a cover sheet and/or an 'Accepted Manuscript' watermark, but excluding any other editing, typesetting or other changes made by IOP Publishing and/or its licensors"

This Accepted Manuscript is (c) 2017 IOP Publishing Ltd.

During the embargo period (the 12 month period from the publication of the Version of Record of this article), the Accepted Manuscript is fully protected by copyright and cannot be reused or reposted elsewhere.

As the Version of Record of this article is going to be / has been published on a subscription basis, this Accepted Manuscript is available for reuse under a CC BY-NC-ND 3.0 licence after the 12 month embargo period.

After the embargo period, everyone is permitted to use copy and redistribute this article for non-commercial purposes only, provided that they adhere to all the terms of the licence https://creativecommons.org/licences/by-nc-nd/3.0

Although reasonable endeavours have been taken to obtain all necessary permissions from third parties to include their copyrighted content within this article, their full citation and copyright line may not be present in this Accepted Manuscript version. Before using any content from this article, please refer to the Version of Record on IOPscience once published for full citation and copyright details, as permissions will likely be required. All third party content is fully copyright protected, unless specifically stated otherwise in the figure caption in the Version of Record.

View the article online for updates and enhancements. 


\section{Osteogenic effects of simvastatin-loaded mesoporous}

\section{titania thin films}

Miriam López-Álvarez ${ }^{1 *}$, Vanesa López-Puente ${ }^{2}$, Cosme Rodríguez-Valencia ${ }^{1}$

Paula C. Angelomé ${ }^{3}$, Luis M. Liz-Marzán ${ }^{4,5,6}$, Julia Serra ${ }^{1}$, Isabel PastorizaSantos ${ }^{2}$, Pío González ${ }^{1}$

${ }^{1}$ New Materials Group, Applied Physics Dpt, IISGS, University of Vigo, Spain

${ }^{2}$ Departamento de Química-Física, CINBIO, Universidade de Vigo, 36310, Spain

${ }^{3}$ Gerencia Química, Centro Atómico Constituyentes, Comisión Nacional de Energía Atómica, CONICET, Av. Gral Paz 1499, B1650KNA, San Martín, Buenos Aires, Argentina

${ }^{4}$ CIC biomaGUNE, Paseo de Míramón 182, 20014 Donostia-San Sebastián, Spain ${ }^{5}$ Ikerbasque Basque Foundation for Science, 48013 Bilbao, Spain

${ }^{6}$ CIBER de Bioingeniería, Biomateriales y Nanomedicina, CIBER-BBN, 20014 Donostia-San Sebastián, Spain

E-mail addresses: miriammsd@uvigo.es, vanelope@uvigo.es, cosme@uvigo.es, angelome@cnea.gov.ar,_llizmarzan@cicbiomagune.es,_jserra@uvigo.es, pastoriza@uvigo.es,pglez@uvigo.es

Corresponding author: Miriam López Álvarez, New Materials Group, Applied Physics Dpt., School of Industrial Engineering, Campus Lagoas-Marcosende,

University of Vigo, 36310, Spain

E-mail:miriammsd@uvigo.es

Telephone: +34 986130158 // Fax: +34986812201

Running head: Simvastatin-loaded mesoporous titania thin films 


\section{Abstract}

The use of statins in the field of bone regeneration is under current investigation due to the existing demand for non-toxic anabolic agents capable of enhancing bone formation in cases of substantial loss. Simvastatin, a coenzyme currently prescribed in clinics to inhibit cholesterol biosynthesis, has been proven to promote osteogenic differentiation by stimulating bone formation and inhibiting osteoclasts activity. We present the loading of simvastatin in mesoporous $\mathrm{TiO}_{2}$ thin films toward combining the pro-osteogenic properties of this molecule with the demonstrated bioactivity of titania. $\mathrm{TiO}_{2}$ thin films processing and characterization were carried out, as well as evaluation of MC3T3-E1 preosteoblasts viability when directly incubated with different concentrations of simvastatin, followed by the analysis of osteogenic activity promoted by simvastatin upon loading in the thin films. The accessible porosity of $36 \%$ quantified on the $95 \pm 5 \mathrm{~nm}$ thick mesoporous thin films, together with pore diameters of $5.5 \mathrm{~nm}$, necks between pores of $2.8 \mathrm{~nm}$ and interpore distances of $12 \pm 2 \mathrm{~nm}$ allow the loading of the simvastatin molecule, as confirmed by FTIR spectroscopy. Simvastatin was found to promote MC3T3-E1 preosteoblasts viability at concentrations $\leq 0.01 \mathrm{~g} / \mathrm{L}$, with a cytotoxicity threshold of 0.05 $\mathrm{g} / \mathrm{L}$. We additionally found that film loadings with $0.001 \mathrm{~g} / \mathrm{L}$ simvastatin promotes statistically higher MC3T3-E1 pre-osteoblast proliferation whereas a higher concentration of $0.01 \mathrm{~g} / \mathrm{L}$ leads to statistically higher osteogenic activity (ALP synthesis), after 21 days of incubation, as compared to unloaded films. These results demonstrate the potential of simvastatin local administration based on bioactive mesoporous thin films to promote pro-osteogenic properties. By focusing this strategy on the coating of metallic prostheses, the supply of simyastatin to the target tissue can be favored and risks of systemic side effects will be reduced while enhancing the osteointegration of the implants.

Keywords: simyastatin, mesoporous titania, thin films, osteogenic activity, drug delivery.

\section{Introduction}

The main strategy in clinics to restore functionality in cases of critically damaged bone tissue, such as in osteoporosis (Kanis et al 2013) or periodontal diseases (Sayar et al 2016), comprises its replacement by metallic alloys. These metallic implants (such as $\mathrm{Ti}_{6} \mathrm{Al}_{4} \mathrm{~V}$ alloy) present 
appropriate mechanical properties and biocompatibility. However, limitations in terms of bioactivity and osteointegration are commonly experienced, which give rise to problems at implant fixation, apart from infection and inflammation cases after the implant surgery (Xia et al 2012). Thus, to increase the bioactivity and osteointegration of these implants, cellbiomaterial interactions must be improved. These interactions have been demonstrated to be highly influenced by the stiffness, topography and chemical composition of the implant surfáce (Bellino et al 2013). Bioactive materials favor direct surface formation of apatite in vivo, which subsequently enables bone bonding (Karlsson et al 2015a). Among the wide variety of bioactive materials, titania is considered as a highly suitable biocompatible material for bone-anchoring implants exhibiting little or no toxicity, both in vitro and in vivo (Gertler et al 2010).

Moreover, these ceramics can be deposited as thin films over metallic alloys to provide the cells with a bioactive surface. Evaporation-induced self-assembly (EISA) is a very versatile chemical methodology (Brinker et al 1999) by which mesoporous titania thin films can be easily obtained onto a wide variety of substrates with a tunable mesoscopic topography and controlled wettability, porosity and chemical properties, based on a combination of sol gel chemistry, supramolecular templates and surface modifications (Soler-Illia et al 2012, Sanchez et al 2008). These mesoporous titania thin films have been proven to promote in vivo enhanced initial bone contact and improved distribution of bone tissue. This is due to the highly ordered arrays of monodisperse pores, high specific surface areas and bioactive properties (Meretoja et al 2007), which influence and eventually lead to the control of osteoblast adhesion and proliferation. The improvement of the initial attachment of cells onto the implant surfaces promotes enhanced integration of the implant and longer term stability (Bellino et al 2013).

Mesoporous materials have additionally shown great potential in drug delivery applications to provide and maintain drug concentrations within the therapeutic window for the desired period of time. The unique features of mesoporous biomaterials, such as high specific surface area, and tunable pore-size (with pore diameters between 2 and $50 \mathrm{~nm}$ ), -volume and -symmetry (ordered distribution), allow drug release to occur in a highly reproducible and predictable manner (Karlsson et al 2015a). This is of great interest since it is believed that the local drug loading of 
antibiotics, anti-inflammatory medicines and growth factors, commonly prescribed orally, intravenously, intramuscularly or topically after the implant surgery, contributes to enhancing the efficiency of these drugs, while the classic systemic routes hinder them from reaching the interface of implants and tissues (Xia et al 2012). The controlled local delivery of drugs at the implant might bring an efficient therapeutic treatment, since it would administrate the drug directly at the targeted cells for a prolonged time period, and thus reduce the risk of systemic side effects (Karlsson et al 2015a).

In the specific case of bone-anchoring implants, it has been demonstrated that their osseointegration capacity can be improved by using an inbuilt drug delivery system, such as modified mesoporous composites and mesoporous bioactive glasses, which can locally administer drugs. For instance, Karlsson et al (2015b) proved that the local loading of the osteoporosis bisphosphonate drug alendronate, clinically used by oral administration, promoted more extensive bone formation. Different antibiotics were also loaded at hosting molecules for efficient prevention of infections, as demonstrated by Xia et al (2012) by loading cephalothin in titanium dioxide coatings. Anti-inflammatory drugs (ibuprofen) were also tested by McMaster et al (2012) in collagen-templated bioactive titanium dioxide porous networks.

Simvastatin, a hydroxy-3-methylglutaryl coenzyme A (HMG-CoA) reductase inhibitor, is known to inhibit cholesterol biosynthesis and is currently clinically prescribed for that purpose. Several recent studies have demonstrated that this cholesterol-lowering drug also promotes osteogenic differentiation, stimulating bone formation in vitro and in vivo (Maeda et al 2001, Mundy et al 1999, Yin et al 2012). The mechanism is thought to be related with the promotion of mitochondrial function (cell proliferation) and stimulation of the expression of the bone morphogenic protein-2 (BMP-2), a growth factor involved in osteoblast activation. In addition, simvastatin seems to participate in osteoclast inhibition by stimulating neovascularization (increasing the secretion of vascular endothelial growth factor) (Kheirallah and Almeshaly 2016).

The topical administration of simvastatin has been proposed to improve the pro-angiogenic and pro-osteogenic properties of bioglass putty in rat calvaria critical-size defects without significant 
inflammation, stimulating BMP-2 and VEGF mRNA expression in osteoblasts (Allon et al 2012) compared to bioglass without topical simvastatin up to 4 weeks of implantation. The effects of simvastatin on osteoblastic differentiation in vitro were evaluated by Maeda et al (2001) to demonstrate that simvastatin enhances alkaline phosphatase (ALP) activity and mineralization in a dose- and time-dependent fashion. Mundy et al (1999) injected simvastatin (together with lovastatin) subcutaneously in calvaria of mice, resulting in increased bóne formation; moreover when simvastatin was orally administered in rats, increased cancellous bone volume was also quantified. The use of statins is of great current interest as there is a clear need for non-toxic anabolic agents that will substantially increase bone formation in people who have already suffered substantial bone loss (Mundy et al 1999).

However, the systemic administration of statins has been related to serious side effects that can be avoided by means of local delivery of the molecule. Moreover, clinical studies suggest that orally administered statins may be degraded in the liver, so little of the drug is available to accumulate in bone. If higher doses of systemic applied simvastatin are provided, the risk of liver failure, kidney disease, rhabdomyolysis, myalgia and other side effects increase as well (Kheirallah and Almeshaly 2016). Therefore $\mathrm{TiO}_{2}$-based biomaterials loaded with simvastatin present good prospect as coatings of metallic implants that can provide a combination of local drug delivery and bioactivity (direct bone-bonding capability) to be used for biomedical applications, such as treatment and regeneration of bone defects.

These small molecules that activate the promoter of the bone morphogenetic protein- 2 gene can be readily loaded into the meso-porosity of titania thin films to provide metallic prosthesis with higher osteointegration (due to the bioactivity of the titania film) and with pro-osteogenic properties (due to local simvastatin loading), thereby promoting increased expression of the bone morphogenetic protein-2 (BMP-2) gene in bone cells. The processing and characterization of $\mathrm{TiO}_{2}$ mesoporous coatings, their loading with different concentrations of simvastatin as well as the biological response in terms of proliferation and osteogenic activity of MC3T3-E1 preosteoblasts are the main objectives of the present work. 


\section{Materials and Methods}

\subsection{Mesoporous thin films}

Glass discs (6 $\mathrm{mm}$ in diameter, Thermo Scientific) were sonicated in ethanol for $30 \mathrm{~min}$ and then copiously rinsed with Milli-Q water and stored in water until use. Titania mesoporous thin films were fabricated on the glass disc surfaces through the EISA approach as previously reported (Crepaldi et al 2003). Briefly, a precursor mixture of $\mathrm{TiCl}_{4}$ (Aldrich), Pluronic F127 $\left(\left(\mathrm{HO}\left(\mathrm{CH}_{2} \mathrm{CH}_{2} \mathrm{O}\right)_{106}\left(\mathrm{CH}_{2} \mathrm{CH}\left(\mathrm{CH}_{3}\right) \mathrm{O}\right)_{70}\left(\mathrm{CH}_{2} \mathrm{CH}_{2} \mathrm{O}\right)_{106} \mathrm{OH}\right)\right.$, Sigma), EtOH (pure grade, ACS) and Milli-Q water was prepared. $\mathrm{TiCl}_{4} / \mathrm{EtOH} / \mathrm{F} 127 / \mathrm{H}_{2} \mathrm{O}$ mixtures presented a 1:40:0.005:10 molar ratio of the reagents. Then, $125 \mu \mathrm{L}$ of the freshly prepared mixture was spin-coated (4000 rpm) on top of the glass discs. The deposited films were then placed in $50 \%$ relative humidity chambers (obtained with a $\mathrm{NaBr}$ saturated solution in water) for $24 \mathrm{~h}$ and subjected to a stabilizing thermal treatment comprising two successive $24 \mathrm{~h}$ heating steps at $60{ }^{\circ} \mathrm{C}$ and $120{ }^{\circ} \mathrm{C}$ and a final step at $200{ }^{\circ} \mathrm{C}$ for $2 \mathrm{~h}$. The F127, acting as template, was finally removed by immersing the films in ethanol for 3 days.

\subsection{Physicochemical characterization}

Transmission electron microscopy (TEM) images were obtained with a JEOL JEM 1010 microscope operating at an accelerating voltage of $100 \mathrm{kV}$. Samples for TEM were obtained by scratching the films from the substrate and depositing them on carbon- and FORMVAR-coated copper grids. Scanning electron microscopy (SEM) images from the top and the cross section of the films were obtained with a JEOL JSM-6700 FEG scanning electron microscope operating at an accelerating voltage of $10 \mathrm{kV}$.

The porosity and pore size distribution were assessed by Environmental Ellipsometric Porosimetry with a SE SOPRA GES-5 spectroscopic ellipsometer in microspot configuration. This technique consists of performing spectroscopic ellipsometry measurements while varying water vapor pressure in a controlled humidity chamber. From those measurements, refractive index variation as a function of humidity is obtained and total accessible volume is calculated by using a Lorentz-Lorenz effective medium approximation. The size distribution of pores and 
necks was determined from the adsorption and desorption branches of the isotherms, through the Kelvin equation, taking into account the water contact angle of the sample. The data were analyzed with Winelli software (Boissiere et al 2005, Soler-Illia et al 2012).

Raman spectra were collected using a Renishaw InVia Reflex system. The spectrograph uses high resolution grating $\left(1200 \mathrm{~cm}^{-1}\right)$ with additional band-pass filter optics, a confocal microscope and a 2D-CCD camera. All measurements were made in a confocal microscope' in backscattering geometry using a 20X objective with accumulation times of $10 \mathrm{~s}$ and a excitation laser line of $532 \mathrm{~nm}(\mathrm{Nd}: \mathrm{YAG})$.

Fourier transform infrared (FTIR) spectra were recorded in Transmission mode using a Nicolet 5PCFT-IR spectrometer in the $4000-400 \mathrm{~cm}^{-1}$ range. Samples were prepared by scratching the film and mixing it with $\mathrm{KBr}$, to form a pellet.

\subsection{Determination of cytotoxicity threshold and loading of simvastatin}

The cytotoxicity threshold was first determined in order to select the optimal simvastatin concentrations to be tested. Direct cell seeding of the MC3T3-E1 pre-osteoblasts (ECACC, UK) with a wide range of simvastatin $\left(\mathrm{C}_{25} \mathrm{H}_{38} \mathrm{O}_{5}\right.$, Sigma S6196, >97\% purity) concentrations in ethanol $(5 ; 1 ; 0.5 ; 0.1 ; 0.05 ; 0.01 ; 0.001 ; 0 \mathrm{~g} / \mathrm{L})$ was carried out up to 4 days of incubation. Thus, $20 \mu \mathrm{L}$ aliquots from each concentration were added to the corresponding well (96 well microplate) and once ethanol was evaporated, $100 \mu \mathrm{L}$ of cell suspension $\left(1.7 \times 10^{5} \mathrm{cel} / \mathrm{mL}\right)$ in supplemented MEM-alpha medium (Lonza BE02-002F) were added. After 4 days of incubation, and without medium refreshment to maintain the simvastatin concentrations, cell proliferation was quantified with the Cell Proliferation Kit I (MTT assay, Roche), based on the reduction of the yellow tetrazolium salt MTT (3-(4,5-dimethyltiazolyl-2)-2,5-diphenyl tetrazolium bromide) into insoluble purple formazan crystals by the mitochondrial enzyme succinate dehydrogenase, only present in living cells. To this end, $10 \mu \mathrm{L}$ of MTT labeling reagent in phosphate buffered saline (PBS) was added to each well for 4 hours $\left(37^{\circ} \mathrm{C}, 5 \% \mathrm{CO}_{2}\right)$. Formazan crystals were subsequently solubilized with $100 \mu \mathrm{L}$ of $10 \%$ sodium dodecyl sulfate (SDS) in $0.01 \mathrm{M} \mathrm{HCl}$. The plate was incubated overnight and the resulting colored solution was quantified at 595 and 
$655 \mathrm{~nm}$ using a Bio-Rad Model 550 microplate spectrophotometer. Four replicates per condition were evaluated.

The mesoporous $\mathrm{TiO}_{2}$ thin films deposited on glass substrates were then sterilized by immersion in $70 \%$ ethanol for $48 \mathrm{~h}$ at $2-8{ }^{\circ} \mathrm{C}$. After that, ethanol was removed and samples dried in a laminar flow chamber. The loading of $\mathrm{TiO}_{2}$ thin films with simvastatin was performed by addition (discs already placed in 96-well microplates) of $20 \mu \mathrm{L}$ of simvastatin solution in ethanol and maintained for $48 \mathrm{~h}$ at $2-8^{\circ} \mathrm{C}$. Different simvastatin concentrations, $0.01 \mathrm{~g} / \mathrm{L}, 0.001$ $\mathrm{g} / \mathrm{L}$ and $0 \mathrm{~g} / \mathrm{L}$ (reference material), were tested. Finally, the samples were dried in the laminar flow chamber before cell seeding. Simvastatin loaded thin films with a concentration of $5 \mathrm{~g} / \mathrm{L}$ were also characterized by using a Nicolet 5PCFT-IR spectrophotometer in the $4000-400 \mathrm{~cm}^{-1}$ range. Samples were prepared by scratching the film and mixing it with $\mathrm{KBr}$, to form a pellet.

\subsection{Biological response of simvastatin-loaded mesoporous thin films}

A concentration of $1.7 \times 10^{5}$ cells $/ \mathrm{mL}$ of MC3T3-E1 pre-osteoblasts in $100 \mu \mathrm{L}$ of MEM-alpha supplemented with $10 \%$ Fetal Bovine Serum (FBS; Lonza DE14-801E) and $1 \%$ Antibiotic Antimycotic Solution with 10000 units of penicillin, $10 \mathrm{mg}$ of streptomycin and $25 \mu \mathrm{g}$ of amphotericin B per mL (Sigma A5955) were seeded on the $\mathrm{TiO}_{2}+0.01, \mathrm{TiO}_{2}+0.001$ and $\mathrm{TiO}_{2}$ +0 discs. Empty wells on the microplates (Tissue Culture Polystyrene, TCPS) were also seeded to be used as the gold standard of the cell culture. Cells were cultured up to 21 days in a humidified atmosphere with $5 \% \mathrm{CO}_{2}$ at $37^{\circ} \mathrm{C}$. To induce the differentiation to osteoblasts 2phospho-L-ascorbic acid trisodium salt (2 mM, Sigma 49752), $\beta$-glycerophosphate disodium salt hydrate (10 mM, Sigma G9422) and dexamethasone $\left(10^{-5} \mathrm{M}\right.$, Sigma D4902, $\left.\geq 97 \%\right)$ were added to the supplemented MEM-alpha. Culture medium was renewed every 2-3 days.

Cell morphology was analyzed by SEM (Philips XL30) after 7 and 21 days. After each incubation time, cells were fixed with $2.5 \%$ glutaraldehyde solution in PBS (Lonza BE17512F) for $2 \mathrm{~h}$ at $4{ }^{\circ} \mathrm{C}$. Samples were then washed three times for $30 \mathrm{~min}$ with PBS and dehydrated in graded acetone solutions $(30 \%, 50 \%, 70 \%, 80 \%, 95 \%)$ for 30 minutes in each solution and in absolute acetone for $1 \mathrm{~h}$. After dehydration, samples were submitted to critical 
point in $\mathrm{CO}_{2}$, at 75 atm and $31.3{ }^{\circ} \mathrm{C}$, mounted on metal stubs and sputter-coated with gold prior to their analysis using a Philips XL30 scanning electron microscope (CACTI, University of Vigo).

Cell proliferation was quantified after 7 and 21 days with the Cell Proliferation Kit I (MTT assay, Roche), as described above. The plate was then incubated overnight and, after removing the discs, the resulting colored solution was quantified at 595 and $655 \mathrm{~nm}$ using a Bio-Rad Model 550 microplate spectrophotometer. Four replicates per material per condition were evaluated and the complete experiment was repeated twice. $\mathrm{TiO}_{2}$ discs without cell seeding were also incubated as blanks.

Osteogenic activity was evaluated by quantifying the activity of the enzyme alkaline phosphatase (ALP) after 7 and 21 days of incubation. After each incubation time, discs were carefully rinsed twice with PBS and immersed in water. The cell lysates were obtained after the osmotic shock followed by a thermal shock by transferring the lysates from 37 to $-80{ }^{\circ} \mathrm{C}$. ALP activity was measured using a p-nitrophenol assay. Briefly, p-nitrophenyl phosphate, which is colorless, was hydrolyzed by alkaline phosphatase at $\mathrm{pH} 10.5$ and $37{ }^{\circ} \mathrm{C}$ to form free $\mathrm{p}$ nitrophenol, which is yellow. The reaction was stopped by adding $\mathrm{NaOH}$ and the absorbance read at $405 \mathrm{~nm}$ in a microplate reader (Bio-Tek, USA). The kit (Alkaline Phosphatase Assay Kit, Abcam) provides with ALP standards to calibrate the results and obtain the corresponding concentrations of enzyme $(\mathrm{U} / \mathrm{mL})$ from the absorbance data. Both cell proliferation and osteogenic activity protocols were also applied to the TCPS controls, as the gold standard reference. Four replicates were used per material per condition and the complete experiments were repeated twice. Discs without cell seeding were also incubated as blanks.

\subsection{Statistical analysis}

Data are presented as mean \pm mean standard deviation (typical error) in error bars $(n=4)$. Differences between groups were analyzed according to Student's t-test with $p<0.01$ and $p<0.05$ considered statistically significant (99\% and $95 \%$ of cases, respectively).

\section{Results}




\subsection{Mesoporous thin films characterization and simvastatin loading}

Mesoporous titania thin films were fabricated on glass disks by spin coating following the EISA procedure (Crepaldi et al 2003). An amphiphilic block-copolymer (Pluronic F127) was employed as pore template and $\mathrm{TiCl}_{4}$ was used as $\mathrm{TiO}_{2}$ precursor, both dissolved in ethanol. The controlled evaporation of the solvent led to assembly of the Pluronic F127 into micelles and the condensation of the precursor, generating an ordered mesophase. Stiffening of the inorganic network and removal of the template required a thermal treatment and ethanol extraction/Figure 1 shows scanning and transmission electron micrographs of the obtained thin films. Highly ordered pores forming a 3D cubic arrangement compatible with the $\operatorname{Im} 3 \mathrm{~m}$ space group (body centered cubic order, commonly obtained when using Pluronic F127 as a template (Crepaldi et al 2003)) were observed. The interpore distance (from center to center of neighboring pores) for these mesoporous films was of $12 \pm 2 \mathrm{~nm}$, as determined from TEM and SEM image analysis. This value is in accordance with previously reported results (Crepaldi et al 2003). A film thickness of $95 \pm 5 \mathrm{~nm}$ was measured from SEM cross section images (inset in figure 1(a)).

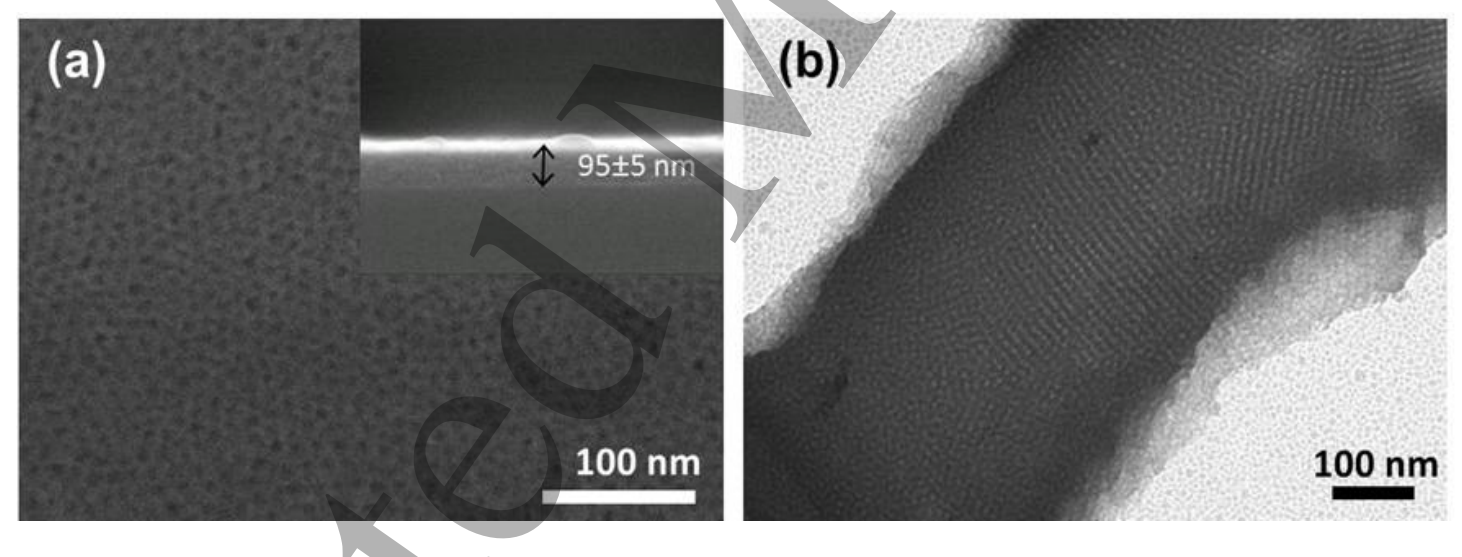

Figure 1. SEM (a) and TEM micrographs (b) of mesoporous titania thin films deposited on a glass disc. In (a) the inset is an image of the cross section of the same mesoporous thin film.

The removal of Pluronic F127 upon ethanol extraction (see experimental part for details) was evaluated by FTIR analysis and confirmed by the absence of the strong IR signals at around 2850-2930 $\mathrm{cm}^{-1}$ assigned to the $\mathrm{C}-\mathrm{H}$ stretching vibration of the template (figure $\mathrm{S} 1$ (a) in supporting material) (Socrates et al 2004). The crystalline structure of $\mathrm{TiO}_{2}$ was evaluated by Raman spectroscopy, which revealed the characteristic lines of anatase $\mathrm{TiO}_{2}$ phase at $150(\mathrm{Eg})$, 
194, $400(\mathrm{~B} 1 \mathrm{~g})$, and $636(\mathrm{Eg}) \mathrm{cm}^{-1}$ (figure $\mathrm{S} 1(\mathrm{~b})$ in supporting material) (Wang et al 2013). However, broad of peaks at 400 and $636 \mathrm{~cm}^{-1}$ indicates that the titania walls present a low degree of crystalline order, in agreement with previous results (Angelomé PC et al 2007).

Finally, the accessible porosity and the pore size distribution of the mesoporous thin films were evaluated by Environmental Ellipsometric Porosimetry (figure 2). The adsorption-desorption isotherms shown in figure 2(a) are characteristic of mesoporous materials and demonstrate that the accessible porosity of the obtained titania mesoporous thin film was around $36 \%$. The pore size distribution plotted in figure 2(b) corresponds to pores of $5.5 \mathrm{~nm}$ (obtained from the adsorption branch) and necks between the pores of $2.8 \mathrm{~nm}$ (obtained from desorption branch). The porosity and pore sizes are again in agreement with previous results obtained for calcined mesoporous films (Violi et al 2012), which confirms the efficiency of the extraction approach to eliminate the template.

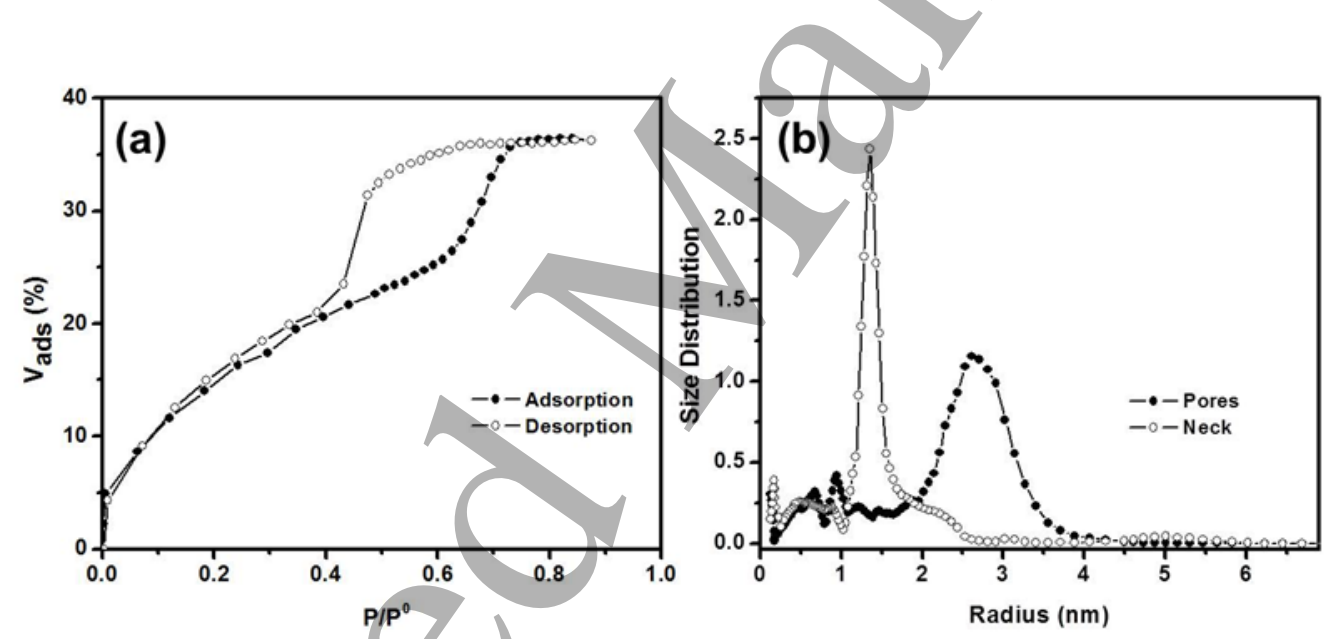

Figure 2. Water adsorption-desorption isotherms for a mesoporous titania thin film (a). Pore size (solid circles) and neck size (empty circle) distributions obtained from adsorption-desorption branches of isotherms through the Kelvin equation (b).

The high porosity of the mesoporous titania thin films together with their bioactive properties motivated us to load the mesostructures with simvastatin. Importantly, simvastatin is a molecule (see figure S2 in supporting information) with dimensions smaller than the mesoporous pore and neck sizes. In addition, the molecule presents ester and hydroxyl groups, which are known to be complexing agents for mesoporous $\mathrm{TiO}_{2}$ (Angelomé and Soler-Illia 2005).The ability of 
simvastatin to diffuse within the mesoporous thin film and attach to the $\mathrm{TiO}_{2}$ walls was confirmed by FTIR spectroscopy. As shown in figure 3, the FTIR spectrum of a titania thin film loaded with $5 \mathrm{~g} / \mathrm{L}$ of simvastatin displays the characteristic FTIR signals of this molecule, including symmetric and asymmetric stretching vibration of $\mathrm{C}-\mathrm{H}\left(2800-3000 \mathrm{~cm}^{-1}\right.$ and 1456 $\left.\mathrm{cm}^{-1}\right)$, esteric carbonyl $\mathrm{C}=\mathrm{O}$ stretch $\left(1695 \mathrm{~cm}^{-1}\right)$ and bending of both $\mathrm{C}-\mathrm{O}-\mathrm{C}$ lactone $\left(1265 \mathrm{~cm}^{-1}\right)$ and ester $\left(1161 \mathrm{~cm}^{-1}\right)$ (Ledeti et al 2015), together with the $v_{\mathrm{TTOTi}}$ vibrations of the oxide.

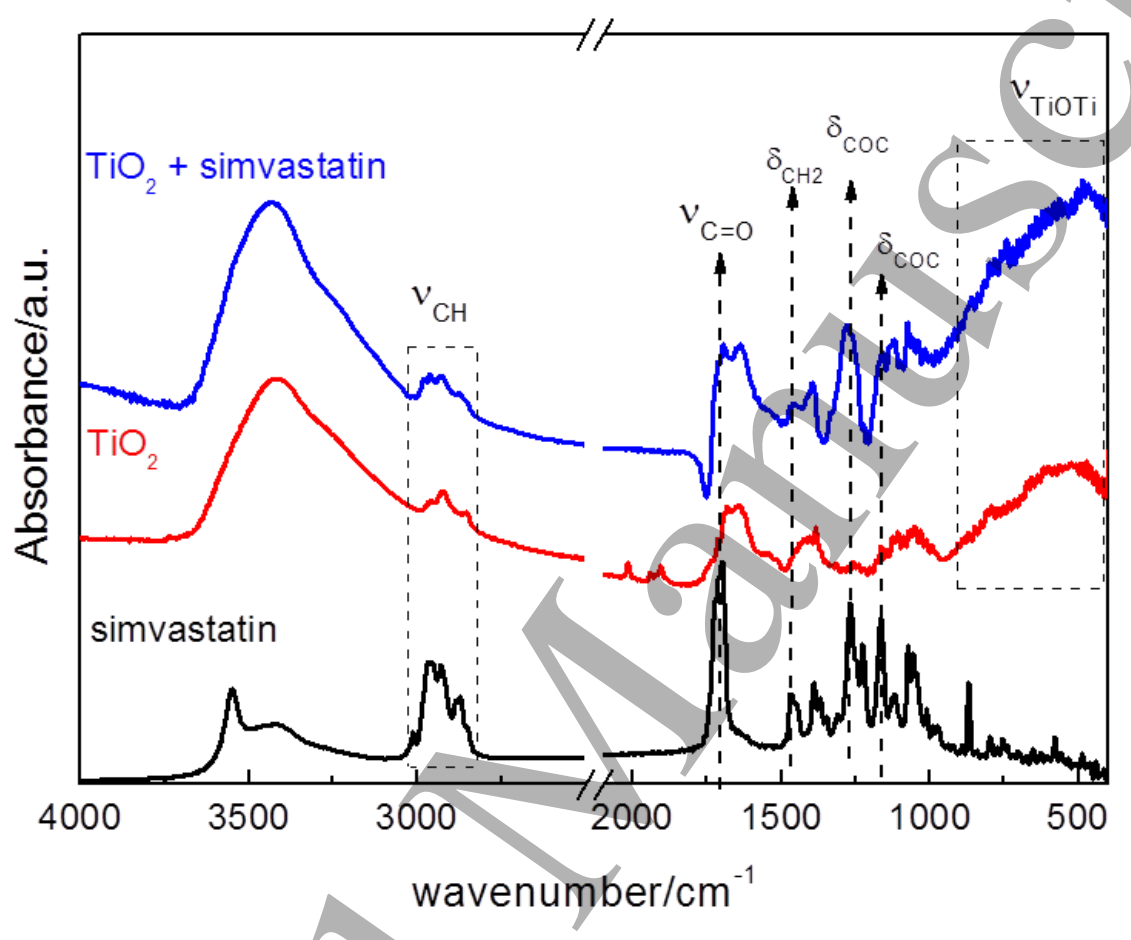

Figure 3. FTIR spectra of simvastatin (black), a mesoporous titania thin film (red) and a mesoporous titania thin film loaded with simvastatin (blue).

\subsection{Biological response of simvastatin-loaded mesoporous thin films}

Figure 4 presents the direct evaluation of MC3T3-E1 pre-osteoblasts viability with a wide range of simvastatin concentrations from $0 \mathrm{~g} / \mathrm{L}$ to $5 \mathrm{~g} / \mathrm{L}$, in the growth media. The samples with $0 \mathrm{~g} / \mathrm{L}$ were considered as the positive control for optimal cell viability. After 4 days of incubation, simvastatin concentrations $\leq 0.01 \mathrm{~g} / \mathrm{L}$ promoted cell viability within the same range as the $0 \mathrm{~g} / \mathrm{L}$ (for $0.01 \mathrm{~g} / \mathrm{L}$ ) or statistically significantly higher $(\mathrm{p}<0.01$ ) (for $0.001 \mathrm{~g} / \mathrm{L}$ ) than both $0 \mathrm{~g} / \mathrm{L}$ and $0.01 \mathrm{~g} / \mathrm{L}$ concentrations. However, higher simvastatin concentrations $\geq 0.1 \mathrm{~g} / \mathrm{L}$ (from 0.1 to 5 $\mathrm{g} / \mathrm{L}$ ) were found to promote low cell viability, with optical density values below 0.4 which is 
considered as a cytotoxic level, and significantly lower cell viability $(\mathrm{p}<0.01)$ than the positive control $(0 \mathrm{~g} / \mathrm{L})$ for all cases. The $0.05 \mathrm{~g} / \mathrm{L}$ samples promoted higher cell viability $(>0.4)$, but still statistically significantly lower $(\mathrm{p}<0.01)$ than the positive control. Therefore, taking into account these results, the cytotoxicity threshold for simvastatin with MC3T3-E1 pre-osteoblasts could be established on simvastatin concentrations $\geq 0.05 \mathrm{~g} / \mathrm{L}$. Moreover $0.01 \mathrm{~g} / \mathrm{L}$ and $0.001 \mathrm{~g} / \mathrm{L}$ were considered as the optimal simvastatin concentrations to be loaded within the mesoporous titania thin films, as they seemed to ensure the same levels of cell viability or higher (in case of $0.001 \mathrm{~g} / \mathrm{L}$ ) than the growth medium (without simvastatin).

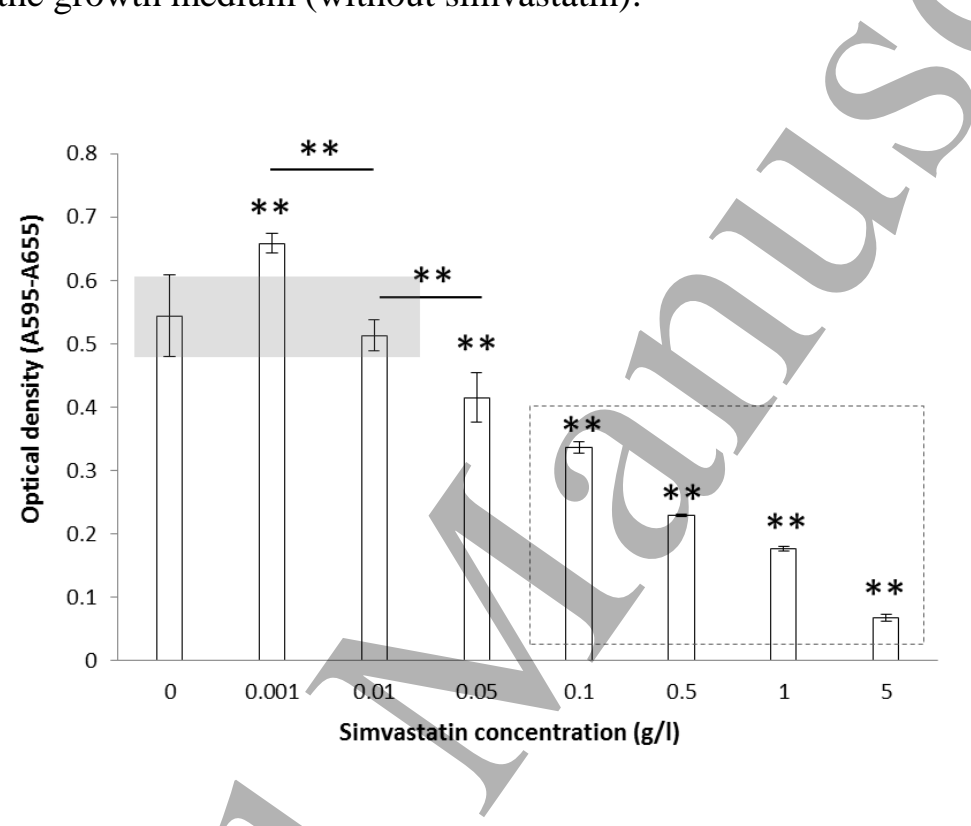

Figure 4. MC3T3-E1 pre-osteoblasts viability after 4 days of incubation with different concentrations $(\mathrm{g} / \mathrm{L})$ of simyastatin in supplemented MEM-alpha growth medium. Significant statistical differences are presented as $* *$ for $p<0.01(99 \%)$ and $*$ for $p<0.05(95 \%)$.

$\mathrm{TiO}_{2}$ thin films were then loaded with the two optimal simvastatin concentrations of $0.01 \mathrm{~g} / \mathrm{L}$ and $0.001 \mathrm{~g} / \mathrm{L}$ and incubated with MC3T3-E1 pre-osteoblasts to evaluate their proliferation and osteogenic activity. MC3T3-E1 pre-osteoblasts proliferation on the loaded thin film coatings together with the experimental controls $(0 \mathrm{~g} / \mathrm{L}$ and TCPS $)$ is presented in figure 5 , as a function of incubation time ( 7 and 21 days). Cell proliferation on the three tested mesoporous titania thin films was significantly lower $(\mathrm{p}<0.01)$ than on the TCPS after 7 days of incubation, where the optical density value above 1.0 at this latter validated the healthy stage of the cells. After 21 
days of incubation, no statistical differences were found between cell proliferation at $0 \mathrm{~g} / \mathrm{L}$ mesoporous titania thin films and TCPS, thereby validating the biocompatibility of the films together with their proper sterilization and the optimal evaporation of ethanol during the loading procedure (as these $0 \mathrm{~g} / \mathrm{L}$ samples were subjected to the same process as the loaded ones). Moreover, cell proliferation increased for all tested conditions, as compared to each value at 7 days. In more detail, cell proliferation at $0.01 \mathrm{~g} / \mathrm{L}$ was significantly lower $(\mathrm{p}<0.01)$ than $/$ on $0.001 \mathrm{~g} / \mathrm{L}$ and $0 \mathrm{~g} / \mathrm{L}$ mesoporous thin films. On the other hand, the $0.001 \mathrm{~g} / \mathrm{L}$ films promoted significantly higher cell proliferation than the $0.01 \mathrm{~g} / \mathrm{L}(\mathrm{p}<0.01)$ and the $0 \mathrm{~g} / \mathrm{L}(\mathrm{p}<0.01)$ films. We therefore conclude that, loading of mesoporous titania thin films with $0.001 \mathrm{~g} / \mathrm{L}$ simvastatin significantly promoted the proliferation of MC3T3-E1 pre-osteoblasts after 21 days of incubation, while the cell proliferation rate in case of $0.01 \mathrm{~g} / \mathrm{L}$ loading was significantly slowed down.

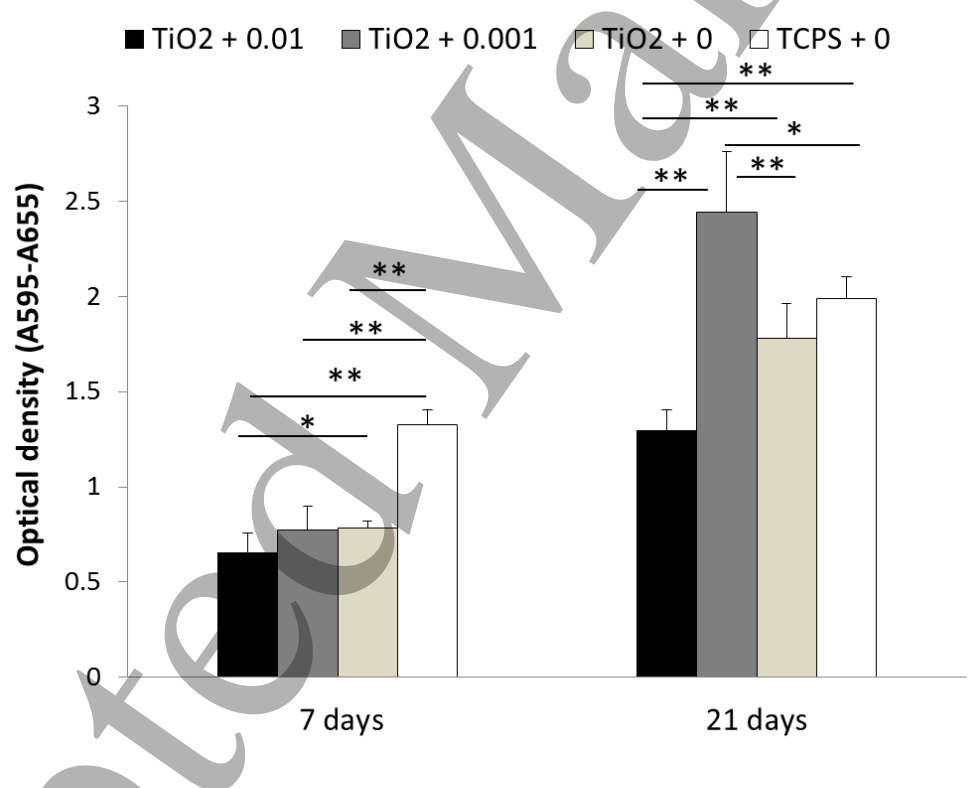

Figure 5. MC3T3-E1 pre-osteoblasts proliferation on mesoporous titania thin films loaded with $0.01 \mathrm{~g} / \mathrm{L}, 0.001 \mathrm{~g} / \mathrm{L}$ and $0 \mathrm{~g} / \mathrm{L}$ of simvastatin up to 21 days of incubation. Cell proliferation for tissue culture polystyrene (TCPS) is also presented.

The effect of simvastatin loaded titania thin films on cell morphology after 21 days of incubation was analyzed by SEM. Figure 6 shows SEM micrographs of MC3T3-E1 preosteoblasts monolayers on thin films loaded with simvastatin at the $0.01 \mathrm{~g} / \mathrm{L}(\mathrm{a}, \mathrm{b}), 0.001 \mathrm{~g} / \mathrm{L}$ (c, 
d) and $0 \mathrm{~g} / \mathrm{L}(\mathrm{e}, \mathrm{f})$. It is important to note that a cell monolayer covering the whole film surface was observed in all cases (figure 6a,c,e). Meanwhile, formation of complex filament networks and synthesis of pre-mineralized matrix were evident in $0.01 \mathrm{~g} / \mathrm{L}$ (figure $6(\mathrm{~b})$ ) and $0 \mathrm{~g} / \mathrm{L}$ (figure 6 (f)) thin films, and less intense in the case of $0.001 \mathrm{~g} / \mathrm{L}$ (figure $6(\mathrm{~d})$ ).
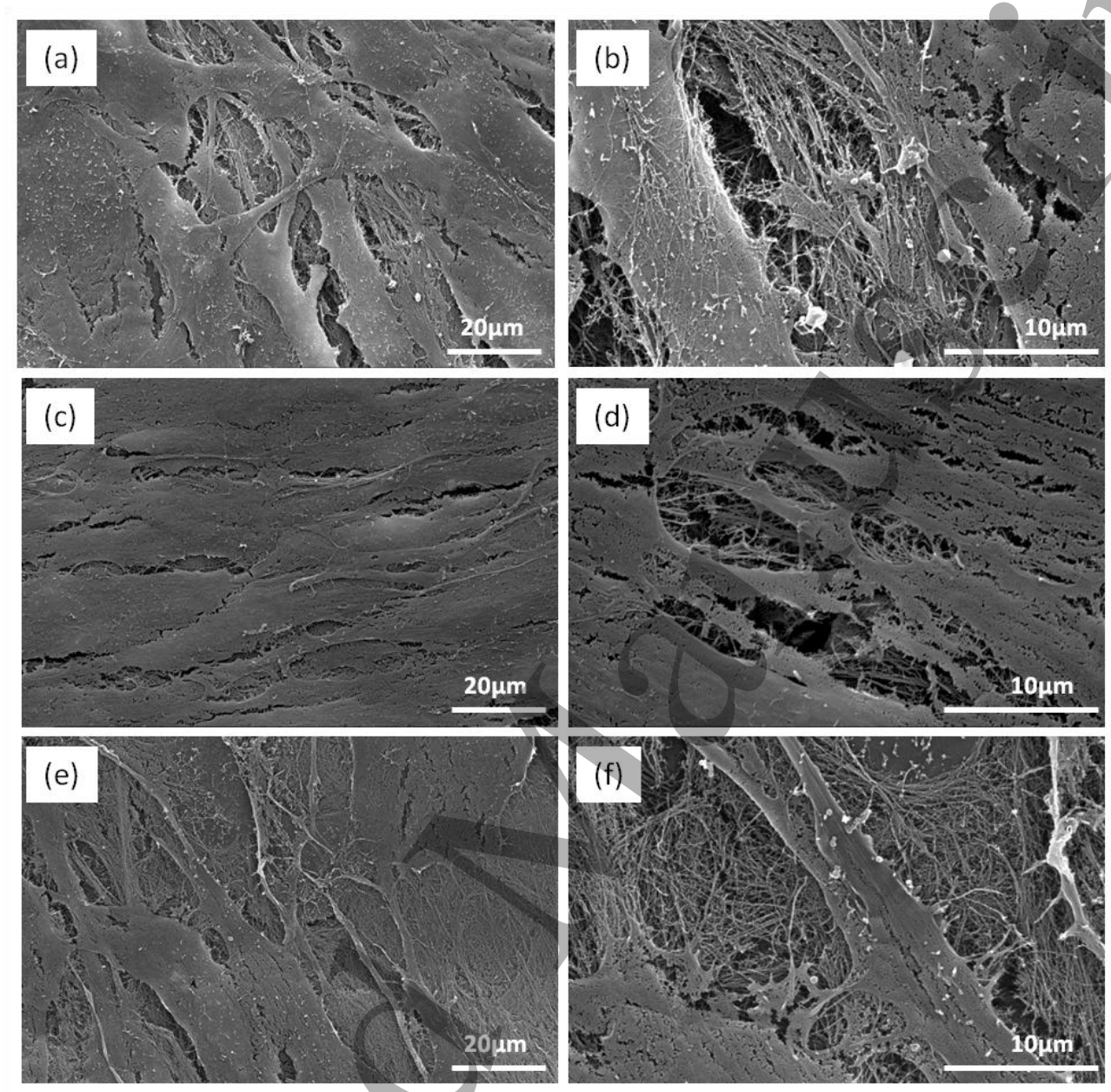

Figure 6. SEM micrographs of MC3T3-E1 pre-osteoblasts morphology on $0.01 \mathrm{~g} / \mathrm{L}(\mathrm{a}, \mathrm{b}), 0.001$ $\mathrm{g} / \mathrm{L}(\mathrm{c}, \mathrm{d})$ and $0 \mathrm{~g} / \mathrm{L}(\mathrm{e}, \mathrm{f})$ simvastatin loaded mesoporous titania thin films after 21 days of incubation.

The osteogenic activity of the MC3T3-E1 pre-osteoblasts was evaluated by quantifying the synthesis of the early marker alkaline phosphatase (ALP enzyme) after 7 and 21 days (figure 7). Thus, the dramatic and expected increase at the ALP synthesis by the cells at 21 days of incubation on the TCPS, compared to the value quantified at 7 days, validated the healthy stage of the cells and, therefore, the experiment. Focusing on the titania thin films, the absence of 
ALP synthesis was observed at 7 days of incubation, being significantly lower $(p<0.01)$ than in TCPS. A dramatic increase of ALP synthesis was also detected for the three tested titania thin films at 21 days of incubation, in analogy to TCPS, which proved the differentiation of the MC3T3-E1 pre-osteoblast like cells into osteoblasts. However differences were found between them, with significantly higher values for $0.01 \mathrm{~g} / \mathrm{L}$ of simvastatin than for the two other films with lower concentrations: $0.001(\mathrm{p}<0.05)$ and $0 \mathrm{~g} / \mathrm{L}(\mathrm{p}<0.01)$. These two lower concentrations presented also significantly lower ALP synthesis than the TCPS $(p<0.05$ and $p<0.01$, respectively), while the 0.01 promoted the osteogenic activity at the same level than the gold standard.

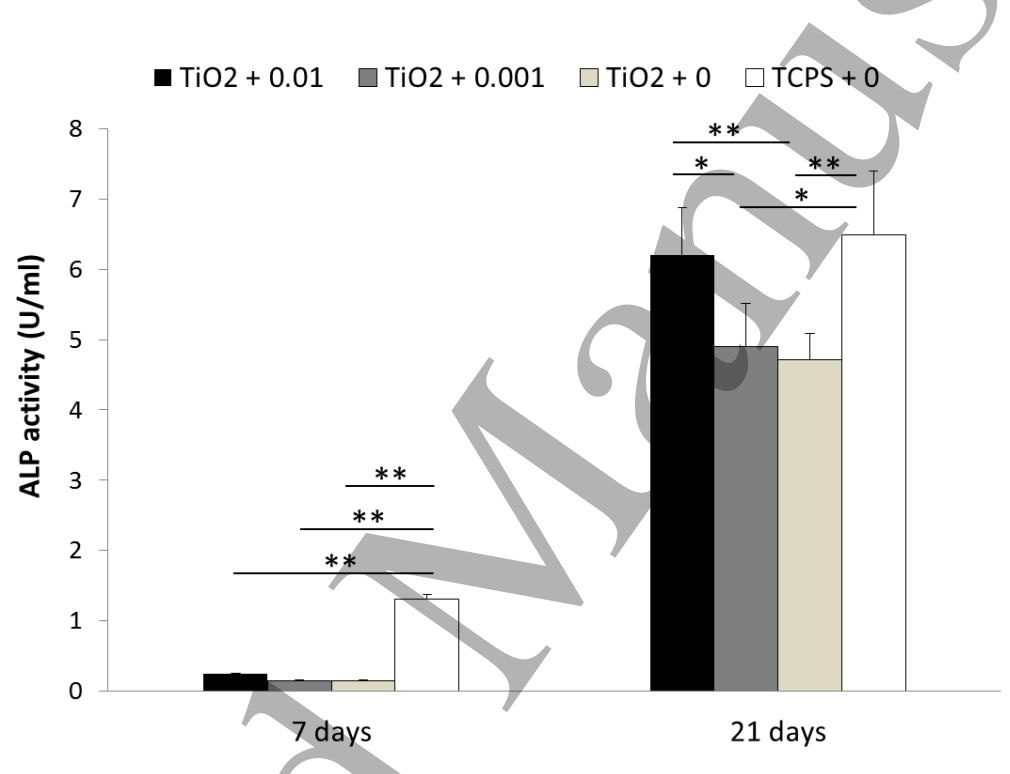

Figure 7. MC3T3-E1 pre-osteoblasts osteogenic activity (ALP synthesis) on mesoporous titania thin films loaded with $0.01 \mathrm{~g} / \mathrm{L}, 0.001 \mathrm{~g} / \mathrm{L}$ and $0 \mathrm{~g} / \mathrm{L}$ of simvastatin up to 21 days of incubation. ALP synthesis quantified on the tissue culture polystyrene (TCPS) is also presented.

In figure 8 the SEM analysis of the cell monolayer microstructure at 21 days of incubation on the $0.01 \mathrm{~g} / \mathrm{L}$ thin films is presented. At this time of incubation, cells are found to spread on a flat morphology (figure 8(a)) with abundant lamellipodia to establish cell to cell contacts covering the entire surface and growing directly over cell layer (figure 8(b)), being the thin film under the thick layer of cells. The synthesis of pre-mineralized extracellular matrix can be observed with the formation of a complex network of pre-collagen filaments (figure 8c,d). 

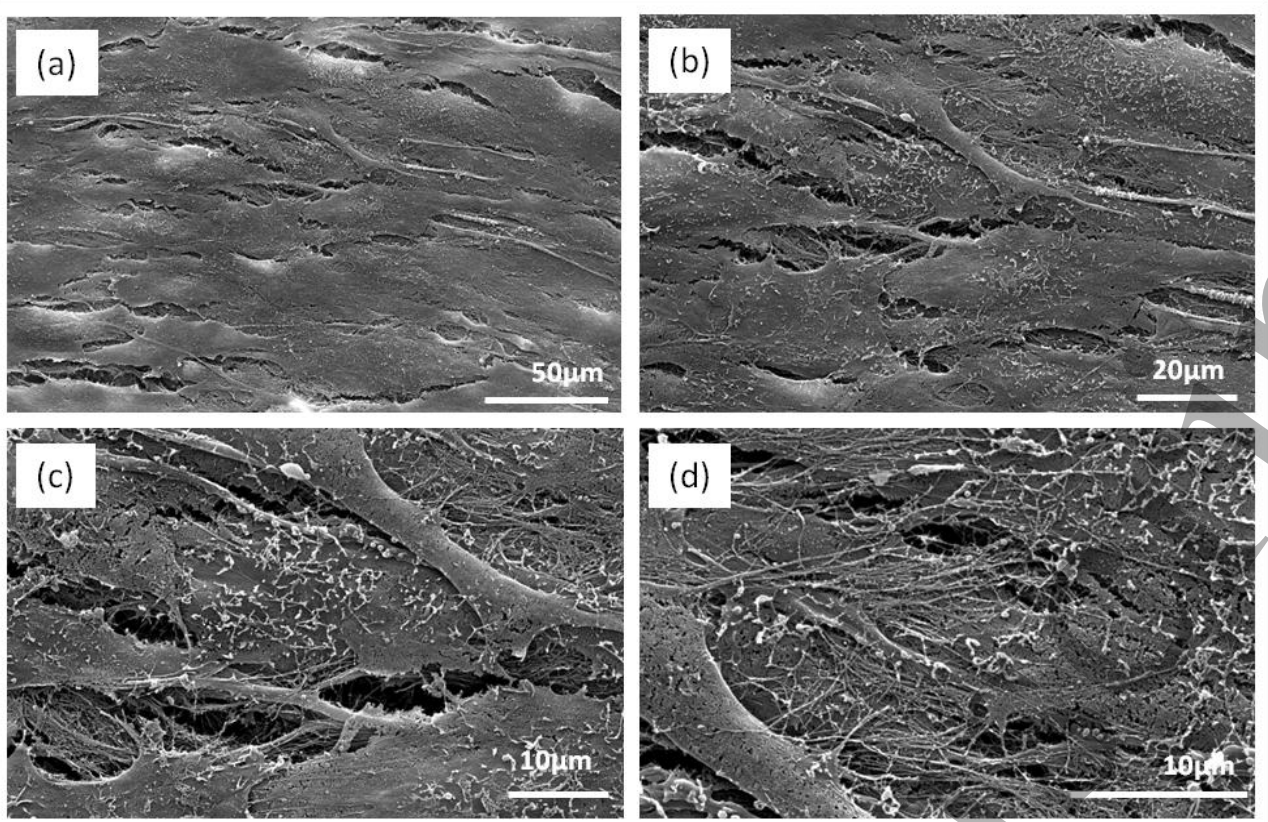

Figure 8. SEM micrographs of MC3T3-E1 pre-osteoblasts morphology on mesoporous titania thin films loaded with $0.01 \mathrm{~g} / \mathrm{L}$ of simvastatin after 21 days of incubation.

\section{Discussion}

In the present work, the promotion of osteogenic activity by simvastastin upon loading in mesoporous titania thin films was evaluated on MC3T3-E1 pre-osteoblasts, along with the cytotoxicity threshold.

In detail, simvastatin loading within mesoporous titania thin films was confirmed together with the physicochemical characterization of the films. The abundance of highly ordered pores forming a 3D cubic arrangement was proved on the mesoporous thin films of $\mathrm{TiO}_{2}$, with an interpore distance of $12 \pm 2 \mathrm{~nm}$ and a layer thickness of $95 \pm 5 \mathrm{~nm}$, as presented in figure 1 . The accessible porosity was quantified (figure 2) to be $36 \%$, with pore diameters of $5.5 \mathrm{~nm}$ and necks between the pores of $2.8 \mathrm{~nm}$. These data, together with the simvastatin dimensions $(1.2$ $\mathrm{nm} \times 1.2 \mathrm{~nm}$ ) ensure the ability of the molecule to diffuse within the pores and attach to the titania walls, through ester and hydroxyl groups. Simvastatin loading was confirmed by FTIR spectroscopy (figure 3) where $v_{\mathrm{C}=\mathrm{O}}, v_{\mathrm{CH}}$ and $v_{\mathrm{COC}}$ vibrations were detected, together with $v_{\text {TiOTi }}$ vibrations assigned to the mesoporous film. An enhanced osteointegration was previously 
observed for mesoporous titania with $6 \mathrm{~nm}$ of pore diameter (Harmankaya et al 2013, Galli et al 2014, Karlsson et al 2015b).

The ability of mesoporous titania to form chemical bonds with apatite through $\mathrm{Ca}^{2+}$ cations (Karlsson et al 2014), in combination with its suitability as drug delivery system, render it unique properties when used as implant coatings. The loading of different bone formation promoters in mesoporous titania films (alendronate (Karlsson et al 2015b), raloxiféne (Harmankaya et al 2013) or magnesium (Galli et al 2014)) has been reported. In this context, the loading and osteogenic activity promoted by simvastatin are of interest, as it is currently prescribed to inhibit cholesterol biosynthesis and already proven as a promoter of osteogenic differentiation (Maeda et al 2001).

When simvastatin was directly added to the cells in growth media (figure 4) promoted MC3T3E1 pre-osteoblasts viability at concentrations $\leq 0.01 \mathrm{~g} / \mathrm{L}$, but inhibited viability at higher concentrations $\geq 0.1 \mathrm{~g} / \mathrm{L}$, with a cytotoxicity threshold at $0.05 \mathrm{~g} / \mathrm{L}$. This viability trend was maintained upon simvastatin loading into mesoporous titania thin films. Indeed, concentrations of $0.01 \mathrm{~g} / \mathrm{L}$ and $0.001 \mathrm{~g} / \mathrm{L}$ of simvastatin promoted the MC3T3-E1 proliferation, being statistically higher for $0.001 \mathrm{~g} / \mathrm{L}$ (figures 5 and 6), and the osteogenic activity, being statistically higher for $0.01 \mathrm{~g} / \mathrm{L}$ (figures 7 and 8) after 21 days of incubation. Maeda et al (2001) proved higher levels of osteoblast differentiation, and mineralization when $10^{-7} \mathrm{M}$ simvastatin was directly added to MC3T3-E1, as compared to $10^{-8}$ and $10^{-9} \mathrm{M}$. In our work the highest osteoblast differentiation was achieved for $0.001 \mathrm{~g} / \mathrm{L}\left(2.4 \times 10^{-6} \mathrm{M}\right)$ and $0.01 \mathrm{~g} / \mathrm{L}\left(2.4 \times 10^{-5} \mathrm{M}\right)$ upon loading in the thin films. Moreover, the cytotoxicity threshold obtained when cells were directly incubated with simvastatin was established as $0.05 \mathrm{~g} / \mathrm{L}\left(1.2 \times 10^{-4} \mathrm{M}\right)$. These results demonstrate that there was still margin in vitro to enrich with higher concentrations of simvastatin for this cell line.

It is important to note that despite the concentrations of statins in the bone marrow have not been well established yet, it is accepted that osteoblasts and osteoclasts may be exposed to very low concentrations (Kheirallah and Almeshaly 2016). In fact, within the strategy of local administration, the coating of a porous and well interconnected scaffold of $\mathrm{TiO}_{2}$ with alginate 
hydrogel containing $10 \mathrm{nM}$ of simvastatin was reported to promote the osteogenic differentiation of human mesenchymal stem cells (Pullisaar et al 2014). The presence of alginate and the entire scaffold of titania ( $8 \mathrm{~mm}$ in height and $9 \mathrm{~mm}$ in diameter) have surely contributed to these good results for such a low dose of simvastatin, against the thin film titania coatings (95 $\mathrm{nm}$ in height and $6 \mathrm{~mm}$ in diameter) used at the present work.

On the other hand, higher concentrations of simvastatin were also successfully evaluated in tibial defect of rabbit model in terms of osteointegration, bone ingrowth and neovascularization. Thus, Liu et al (2016) evaluated porous titanium alloy scaffolds $(5 \mathrm{~mm}$ diameter and $6 \mathrm{~mm}$ thickness) filled with simvastatin/poloxamer 407 hydrogel with final simvastatin concentrations of $0.1 \mathrm{~g} / \mathrm{L}$ and $0.5 \mathrm{~g} / \mathrm{L}$. A significantly increased cortical bone was quantified with the $0.5 \mathrm{~g} / \mathrm{L}$ simvastatin group $(0.5 \mathrm{mg})$, being nearly identical to that of normal cortical bone at 8 weeks. Moreover, in a recent review about the simvastatin influence on animal model studies (Sendyk et al 2016 the difficulty to equalize the optimal range of doses/concentrations of this drug was discussed. Successful results were found for simvastatin doses which range from $10^{-4}$ to $10^{-7} \mathrm{M}$, when directly applied on titanium implants's surfaces or in calcium phosphate coatings, and from $50 \mu \mathrm{g}$ to $10 \mathrm{mg}$ on oxidized surface of implants, combined with chitosan as a coating or directly injected in to the femurs. However, topical application has been shown to cause local inflammation in high doses (Sendyk et al 2016). There is, therefore, a lack of consensus in the literature in relation to the effective doses of simvastatin, even when being tested alone directly with cells, without any carrier. Moreover, it seems to strongly depend on the drug release patterns from the loading material or administration strategy used.

\section{Conclusions}

The ability of simvastatin to be loaded in mesoporous titania thin films was demonstrated together with its effectiveness in terms of pro-osteogenic activity. In detail, $36 \%$ of accessible porosity with pore diameters of $5.5 \mathrm{~nm}$ interpore distances of $12 \pm 2 \mathrm{~nm}$ in $\mathrm{TiO}_{2}$ thin films with thicknesses of $95 \pm 5 \mathrm{~nm}$, were proven to favor the diffusion of simvastatin within the pores and its attachment to the titania walls through ester and hydroxyl groups. Simvastatin concentrations $\leq 0.01 \mathrm{~g} / \mathrm{L}$ were proven to promote MC3T3-E1 pre-osteoblasts viability, while concentrations $\geq$ 
$0.1 \mathrm{~g} / \mathrm{L}$ inhibited it, being the cytotoxicity threshold established as $0.05 \mathrm{~g} / \mathrm{L}$. Finally, a concentration of $0.001 \mathrm{~g} / \mathrm{L}$ of simvastatin upon loaded on the mesoporous titania thin films promoted statistically higher MC3T3-E1 proliferation and a concentration of $0.01 \mathrm{~g} / \mathrm{L}$ statistically higher osteogenic activity after 21 days in comparison to unloaded films. The in vitro effectiveness of simvastatin loading in mesoporous titania thin films was demonstrated. with potential application in the field of bone regeneration, especially when an implant is required. This work opens the possibility of using $\mathrm{TiO}_{2}$ mesoporous thin films as carriers for local delivery of simvastatin to coat metallic prosthesis and provide them with pro-osteogenic activity and better osteointegration. Deep evaluation on the release pattern of this molecule is required as well as the performance in vivo of metallic implants coated with these simvastatinloaded $\mathrm{TiO}_{2}$ thin films.

\section{Acknowledgements}

This work was partially funded by Xunta de Galicia GRC2013-008 and by the Ministerio de Economía y Competitividad (MINECO, Grant MAT2016-77809-R). M. López-Álvarez and V. López-Puente thank funding from FP7/REFPOT-2012-2013.1 (n-316265) BIOCAPS and Spanish MINECO FPI scholarship, respectively. PCA acknowledges the financial support of ANPCyT (PICT 2012-0111) Technical staff of CACTI (University of Vigo) is gratefully acknowledged.

\section{References}

Allon N, Saxena A, Chambers C and Doctor BP 2012 A new liposome-based gene delivery system targeting lung epithelial cells using endothelin antagonist $J$ Control Release $\mathbf{1 6 0}$ $217-24$

Angelomé PC, Andrini L, Calvo ME, Requejo FG, Bilmes SA and Soler-Illia GJAA 2007 Mesoporous anatase TiO2 films: use of Ti K XANES for the quantification of the nanocrystalline character and substrate effects in the photocatalysis behavior $J$ Phys Chem C 11 10886-93 
Angelomé PC and Soler-Illia GJAA 2005 Organically modified transition-metal oxide mesoporous thin films and xerogels Chem Mater 17 322-31

Bellino MG, Golbert S, de Marzi MC, Soler-Illia GJAA and Desimone MF 2013 Controlled adhesion and proliferation of a human osteoblastic cell line by tuning the nanoporosity of titania and silica coatings Biomater Sci 1 186-9

Boissiere C, Grosso D, Lepoutre S, Nicole L, Bruneau AB and Sanchez C 2005 Porosity ánd mechanical properties of mesoporous thin films assessed by environmental ellipsomtric porosimetry Langmuir 21 12362-71

Brinker CJ, Lu Y, Sellinger A and Fan H 1999 Evaporation-induced self-assembly: nanostructures made easy Adv Mater 11 579-85

Crepaldi EL, Soler-Illia GJAA, Grosso D, Cagnol F, Ribot F and Sanchez C 2003 Controlled formation of highly organized mesoporous titania thin films: from mesostructured hybrids to mesoporous nanoanatase $\mathrm{TiO}_{2} J$ Am Chem Soc 125 9770-86

Galli S, Naito Y, Karlsson J, He W, Miyamoto I, Xue Y, Andersson M, Mustafa K, Wennerberg A and Jimbo R 2014 Local release of magnesíum form mesoporous $\mathrm{TiO}_{2}$ coatings stimulates the peri-implant expression of osteogenic markers and improves osteoconductivity in vivo Acta Biomater 10 5193-201

Gertler G, Fleminger G and Rapaport H 2010 Characterizing the adsorption of peptides to $\mathrm{TiO}_{2}$ in aqueous solutions by liquid chromatography Langmuir $\mathbf{2 6}$ 6457-63

Harmankaya N, Karlsson J, Palmquist A, Halvarsson M, Igawa K, Andersson M and Tengvall P 2013 Raloxifene and alendronate containing thin mesoporous titanium oxide films improve implant fixation to bone Acta Biomater 9 7064-73

Kanis JA, McCloskey EV, Johansson H, Cooper C, Rizzoli R and Reginster JY 2013 European guidance for the diagnosis and management of osteoporosis in postmenopausal women Osteoporos Int 24 23-57

Karlsson J, Sundell G, Thuvander M and Andersson M 2014 Atomically resolved tissue integration Nano Lett 14 4220-3 
Karlsson J, Atefyekta S and Andersson M 2015a Controlling drug delivery kinetics from mesoporous titania thin films by pore size and surface energy Int J Nanomedicine $\mathbf{1 0}$ $4425-36$

Karlsson J, Harmankaya N, Allard S, Palmquist A, Halvarsson M, Tengvall P and Andersson M 2015b Ex vivo alendronate localization at the mesoporous titania implant/bone interface $J$ Mater Sci Mater Med 26 1-8

Kheirallah M and Almeshaly H 2016 Simvastatin, dosage and delivery system for supporting bone regeneration, an update review J Oral Maxillofac Surg Med Pathol 28 205-9

Ledeti I, Vlase G, Vlase T, Suta LM, Todea A and Fulias A 2015 Selection of solid-state excipients for simvastatin dosage forms through thermal and nonthermal techniques $J$ Therm Anal Calorim 121 1093-102

Liu H, Li W, Liu C, Tan J, Wang H, Hai B, Cai H, Leng HJ, Liu ZJ and Song CL 2016 Incorporating simvastatin/poloxamer 407 hydrogel into 3D-printed porous Ti6Al4V scaffolds for the promotion of angiogenesis, osseointegration and bone ingrowth Biofabrication 8045012

Maeda T, Matsunuma A, Kawane T and Horiuchi N 2001 Simvastatin promotes osteoblast differentiation and mineralization in MC3T3-E1 cells Biochem Biophys Res Commun 280 $874-7$

McMaster WA, Wang X and Caruso RA 2012 Collagen-templated bioactive titanium dioxide porous networks for drug delivery ACS Appl Mater Interfaces 4 4717-25

Meretoja VV, Tirri T, Aaritalo V, Walboomers XF, Jansen JA and Narhi TO 2007 Titania and titania-silica coatings for titanium: Comparison of ectopic bone formation within cellseeded scaffolds Tissue Eng 13 855-63

Mundy G, Garrett R, Harris S, Chan J, Chen D, Rossini G, Boyce B, Zhao M and Gutierrez G 1999 Stimulation of bone formation in vitro and in rodents by statins Science 286 1946-9

Pullisaar H, Reseland JE, Haugen HJ, Brinchmann JE and Ostrup E 2014 Simvastatin coating of $\mathrm{TiO}_{2}$ scaffold induces osteogenic differentiation of human adipose tissue-derived mesenchymal stem cells Biochem Biophys Res Commun 447 139-44 


\section{1}

Sanchez C, Boissiere C, Grosso D, Laberty C and Nicole L 2008 Design, synthesis, and properties of inorganic and hybrid thin films having periodically organized nanoporosity Chem Mater 20 682-737

Sayar F, Fallah S, Akhondi N and Jamshidi S 2016 Association of serum lipid indices and statin consumption with periodontal status Oral Dis 22 775-80

Sendik DI, Deboni MCZ, Pannuti CM, Naclerio-Homem MG, Wennerberg A 2016 The influence of statins on osseointegration: a systematic review of animal model studies $J$ Oral Rehabil $\mathbf{4 3} 873-882$

Socrates G 2004 Infrared and Raman characteristic group frequencies: Tables and charts, 3er edition New York Wiley ISBN: 978-0-470-09307-8

Soler-Illia GJAA, Angelomé PC, Fuertes MC, Grosso D and Boissiere C 2012 Critical aspects in the production of periodically ordered mesoporous titania thin films Nanoscale 4 254966

Violi IL, Perez MD, Fuertes MC and Soler-Illia GJAA 2012 Highly ordered accessible and nanocrystalline mesoporous $\mathrm{TiO}_{2}$ thin films on transparent conductive substrates ACS Appl Mater Interfaces 4 4320-30

Wang X, Wu G, Zhou B and Shen J 2013 Optical constants of crystallized $\mathrm{TiO}_{2}$ coatings prepared by sol-gel process Materials 6 2819-30

Xia W, Grandfield K, Hoess A, Ballo A, Cai Y and Engqvist H 2012 Mesoporous titanium dioxide coating for metallic implants J Biomed Mater Res Part B 100B 82-93

Yin H, Shi ZG, Yu YS, Hu J, Wang R, Luan ZP and Guo DH 2012 Protection against osteoporosis by statins is linked to a reduction of oxidative stress and restoration of nitric oxide formation in aged and ovariectomized rats Eur J Pharmacol 674 200-6 